\title{
Concepts and Factors Applicable to the Mea- surement of Range Condition
}

\author{
A.D. WILSON AND G.J. TUPPER
}

\begin{abstract}
The concept of range condition is reanalysed in terms of the nature of changes in land and vegetation and the purpose of measurement. A new framework is outlined which presents range condition as an overall concept based on change in the value of land attributes, relative to their potential value. These attributes include factors such as the composition and quantity of the vegetation, the stability of the soil and the productivity of the land in terms of animals, water yield, or amenity value.

On this basis, indices of change in each attribute may be constructed from vegetation measurements. This will include separate indices of soil stability, animal productivity, and vegetation change (flora conservation), which may or may not be correlated with one another. Range condition cannot be defined by one of these attributes alone, so that the separation of ecological and productivitybased methods is artificial. Overall the importance of soil stability is considered to be greater than productivity, which in turn is greater than vegetation change, but this will depend on the type of land and the dominant land use.
\end{abstract}

The concept of range condition is used to denote the changes in vegetation composition, productivity, and land stability that occur when rangelands are grazed by domestic livestock. The purpose of measuring these changes in condition is based on a concern for the long-term productivity and stability of these rangelands. Condition assessments guide and inform the range manager on the improvement or decline in the long-term productivity of his land. Range productivity is stated as the purpose (if not the basis) of assessment, in the original presentation of the system based on quantitative ecology (Dyksterhuis 1949), so that whatever the basis, knowledge of both ecology and productivity are a part of the concept of range condition.

The predominant products of most rangelands are meat and fibre produced from grazing cattle, sheep and goats. Interest in other aspects, such as water yield or wildlife habitat may be important in particular localities, but overall they are secondary to livestock production. Furthermore, it is significant that the changes we seek to measure have been fashioned by livestock grazing. Hence range condition is measured in terms of the effect of grazing by livestock and wild herbivores on wildlife habitats, but is not used to assess the value of those habitats in the absence of grazing.

Despite general agreement on these concepts, there is considerable differences of opinion on how range condition should be measured. At the theoretical level these differences center on whether emphasis should be given to rangeland productivity or to vegetation change. As the main interest in condition centers on changes in productivity, it is natural for productivity-based methods to be developed (Humphrey 1949, Naveh 1975). On the other hand the so-called ecologically based methods (Smith 1979), which measure vegetation change, are regarded by others as a more fundamental expression of range condition (Dyksterhuis 1949, 1958; Gates 1979). In this framework, productivity is correlated with vegeta-

Authors are assistant-chief and experimental officer, CSIRO, Division of Land Resources Management, Deniliquin, New South Wales, Australia.

Manuscript received January 7,1981 . tion change, but not necessarily on a linear or even on a positive basis.

Recently, the practical deficiencies of the formal ecologically based methods have been detailed by Smith (1979). The first of these is that climax or near-climax vegetation is not necessarily best for a particular use, with the result that management may be directed towards attaining "good" or even "fair", rather than "excellent" condition. At best, this reduces the utility of the measurements because of problems in communication to land managers and the general community, while at worst it may lead to a complete misunderstanding. A common example of this is found in woodlands which have an inherent low animal productivity and which are "improved" by changing the composition towards a grassland. The second problem is that of defining the composition of the climax, which may be quite difficult where factors other than grazing a re involved in determining the botanical composition (e.g. fire). The third problem is that the method must be modified to accommodate the presence of exotic species which have been deliberately introduced to increase forage production. Finally, measures of vegetation change may take no account of increases in erosion rate, which is a more serious manifestation of any change in resource condition. The first three of these difficulties may be overcome by appropriate adjustments. However, these adjustments usually have a production outlook, and in extreme situations may negate the original basis of the method. This raises doubts as to whether the formal structure of ecologically based methods can be sustained.

This paper examines the factors that should be considered in the development of methods of measuring range condition and develops a new theoretical framework which is free of the problems described.

\section{The Concept of Range Condition}

There are many factors or attributes involved in the concept of range condition. The primary attributes are changes in the vegetation, such as the botanical composition of the herbage, its total quantity or cover, and its invasion or emergence from a dominance by inedible shrubs or trees. Secondary changes may occur to soil attributes, such as infiltration rate, nutrient content or soil stability. Finally, changes may occur in production characteristics of the land, such as animal production; water yield, wildlife habitat and amenity value. The common factor in these is that in all cases a change in condition refers to a change in status, relative to the potential, of each parameter within a particular land class. On this basis, the generalized definition of range condition is that it represents the present state of an attribute of a land unit relative to the potential of that attribute on the same land unit (see Stoddart et al. 1975). The term "range condition" is used in a qualitative way to represent the sum of the various attributes of condition, but it is not possible to make this summation quantitative because of problems in summing dissimilar quantities. Nevertheless, within a particular vegetation type the major change in condition may be represented by only one of these attributes and range condition may then be regarded as synonymous with the change in that attribute. In the 
well-known example of Dyksterhuis (1949) the major change was represented by botanical composition and in addition, changes in animal production were correlated with this change. Hence, the one index represented both attributes. However, this correspondence does not occur in all vegetation types, and attempts to make botanical composition a universal definition of range condition (Dyksterhuis 1958), are the basis of the problems detailed earlier.

It may be important here to emphasize the difference between the method and the purpose of measuring condition. The secondary and production characteristics of range condition are unlikely to be measured directly. Rather they will be expressed in terms of an index which is derived from vegetation measurement, so calculated to correlate with the attribute in question. Hence all attributes of condition may be measured in terms of components of vegetation, without suggesting that these are the only parameters of interest.

Another important aspect of range condition is land use. A change in attribute such as botanical composition is not in itself intrinsically good or bad unless interpreted in terms of a land use, such as grazing or conservation. Accelerated soil erosion is a change that may always be considered as undesirable (Ellison et al. 1951), but this is also subject to assessment in terms of acceptable levels of erosion in relation to water yield or animal productivity. This is a part of assessing the importance to be given to each of the attributes of condition and indicates that the overall condition of a land unit cannot be expressed in absolute terms.

\section{Choice of Vegetation Measure}

It is a basic premise that range condition will be measured in terms of the vegetation, whatever the attribute in question may be. A change in vegetation is the first symptom of a change in condition, it is the change which is most easily measured and it is the primary factor which leads to a change in other attributes such as erosion and reduced secondary productivity. It is only in research that direct measurement will be made of the secondary and production attributes, and then the purpose will be to devise an appropriate vegetation measurement that has a positive correlation to an attribute such as production.

Each vegetation measure will place different emphasis on the various growth forms of plants in the community and vary in the importance accorded to each species. Biomass gives primary emphasis to large species and in most rangeland communities most of the information will be confined to less than 10 species. Canopy cover is corrclated with biomass, but gives more emphasis to prostrate plants. Basal cover is a related measure used todetermine the density and composition of perennial grass communities.

Density and species frequency a re measures that are related inversely to species size and hence give relatively greater emphasis to smaller and rarer species. Frequency is related to density (and within a species to biomass) on a curvilinear scale. It is also dependent on vegetation pattern and quadrat size (Greig-Smith 1964) and hence is more complex than the other measures.

The effect of the measure chosen to record vegetation change is illustrated in Table I, using data from two rangeland communities. For the Atriplex vesicaria shrubland, biomass measurement indicates a dominance of $A$. vesicaria, while frequency gives prominence to the grasses, Eragrostis spp. and Enneapogon avenaceus. The relative importance assigned to the loss of $A$. vesicaria by overgrazing will depend on which measure is chosen for recording the change. For the semiarid woodland there are also differences between the methods in the importance afforded to each species. However, the differences are smaller and have less effect on the outcome, because the species represented are all of similar size and distribution.

As each measure emphasizes a different characteristic of the vegetation, an appropriate measure must be chosen with reference to the purpose of assessing range condition. Thus frequency may be the most appropriate measure for assessing the presence of rare species within a reservation and hence the "condition" of land under consideration for conservation purposes. However, most of the attributes of range condition that are of interest center on qualities emphasized by biomass (e.g. animal production) or cover (e.g. erosion). Therefore, it is concluded that there should be primary emphasis on biomass, or a related measure that may reflect biomass, such as the basal cover of perennial grasslands. For most species, canopy cover will be closely related to biomass and may offer a substitute, provided some information is obtained about the biomass-cover relationship of the species to guard against unwanted distortion of the importance of those species.

In this context, biomass is considered to be edible biomass, as this represents the parts of the plants of importance to animals. The stems and trunks of shrubs and trees do not represent a resource, except in terms of forestry, and hence are excluded while land condition is considered in terms of grazing. For inedible species

Table 1. Comparative biomass, foliar cover and frequency data for selected species within Atriplex vesicaria low-shrubland and semiarid low-woodland communities (Wikon and Tupper, unpublished data).

October 1976

A. vesicaria low-shrubland

\begin{tabular}{|c|c|c|c|c|c|c|}
\hline \multirow[b]{2}{*}{ Species } & \multirow{2}{*}{$\begin{array}{l}\text { Biomass } \\
(\mathrm{kg} / \mathrm{ha})\end{array}$} & \multirow{2}{*}{$\begin{array}{c}\text { Cover } \\
(\%)\end{array}$} & \multirow{2}{*}{$\begin{array}{c}\text { Frequency' } \\
(\%)\end{array}$} & \multicolumn{3}{|c|}{ Percent composition } \\
\hline & & & & Biomass & Cover & Frequency \\
\hline $\begin{array}{l}\text { Atriplex vesicaria } \\
\text { Atriplex spp. (biennials) } \\
\text { Enneapogon avenaceus } \\
\text { Eragrostis spp. } \\
\text { Sclerolaena brachyptera }\end{array}$ & $\begin{array}{r}1220 \\
108 \\
190 \\
202 \\
103\end{array}$ & $\begin{array}{r}17.6 \\
5.4 \\
11.3 \\
16.4 \\
2.5\end{array}$ & $\begin{array}{l}43 \\
41 \\
65 \\
80 \\
23\end{array}$ & $\begin{array}{r}67 \\
6 \\
10 \\
11 \\
6\end{array}$ & $\begin{array}{r}33 \\
10 \\
21 \\
31 \\
5\end{array}$ & $\begin{array}{r}17 \\
16 \\
26 \\
32 \\
9\end{array}$ \\
\hline
\end{tabular}

Semi-arid woodland (herbaceous spp.)

October 1978

\begin{tabular}{|c|c|c|c|c|c|c|}
\hline \multirow[b]{2}{*}{ Species } & \multirow{2}{*}{$\begin{array}{l}\text { Biomass } \\
(\mathrm{kg} / \mathrm{ha})\end{array}$} & \multirow{2}{*}{$\begin{array}{c}\text { Cover } \\
(\%)\end{array}$} & \multirow{2}{*}{$\begin{array}{c}\text { Frequency' } \\
\text { (\%) }\end{array}$} & \multicolumn{3}{|c|}{ Percent composition } \\
\hline & & & & Biomass & Cover & Frequency \\
\hline $\begin{array}{l}\text { Aristida jerichoensis } \\
\text { Enteropogon acicularis } \\
\text { Monachather paradoxa } \\
\text { Sclerolaena diacantha } \\
\text { Stipa variabilis } \\
\text { Thyridolepis mitchelliana }\end{array}$ & $\begin{array}{l}56 \\
24 \\
21 \\
39 \\
57 \\
24\end{array}$ & $\begin{array}{l}5.4 \\
1.7 \\
1.5 \\
6.0 \\
9.8 \\
1.7\end{array}$ & $\begin{array}{l}27 \\
33 \\
37 \\
61 \\
80 \\
14\end{array}$ & $\begin{array}{l}25 \\
11 \\
10 \\
18 \\
25 \\
11\end{array}$ & $\begin{array}{r}20 \\
7 \\
6 \\
23 \\
37 \\
7\end{array}$ & $\begin{array}{r}11 \\
13 \\
15 \\
24 \\
32 \\
5\end{array}$ \\
\hline
\end{tabular}

Quadrat size $1 \mathrm{~m}^{2}$ 
within a grazed community (or edible species that are above browsing height), photosynthetic biomass is an appropriate equivalent to edible biomass.

The choice of measure is also related to the practical requirements of determining condition over wide areas of land and repeatedly in time. The condition of rangeland refers to the more permanent changes in the vegetation of a range unit induced by grazing, which are separate from the natural variation in time arising from season and amount of rainfall, and changes in cover and biomass arising from recent utilization by livestock. Hence there is a need to record vegetation in terms of a measure that is insensitive to recent growth and utilization. Unfortunately, such measures are those related to species number, such as density and frequency, which cannot be easily used because they do not represent the quantitative relationships between the species. A number of solutions are possible. The first is to use density or frequency as the basic measure of the vegetation and then to apply appropriate correction factors (which in the case of frequency would also involve power transformation) so that the data may then reflect the biomass or cover expected at the peak of the growing season. More simply, a stablc measure that is correlated to biomass, such as basal cover, may be used in perennial grasslands (Foran et al. 1978, Christie 1978). However, it is unsuitable for other growth forms and may be tedious in arid areas where the basal cover is low. Alternatively, it is possible to reduce the importance of seasonal variation by expressing vegetation change relative to a "control" lightly grazed reference area or to measure at times when grazing is light. It is also possiblc in some communities to correct for utilization by estimating the amount of biomass or cover removed by grazing.

The requirement for assessment over wide areas of land in a minimum of time indicates that the most useful method will be one which is capable of both measurement and estimation. Estimates will be used in survey situations, but these will be based on training and checking by measurement, and bc consistent with information derived from research situations where measurement is used. This requirement also favours biomass and cover which are easier to estimate than the more complex measure, frequency.

\section{Selection and Classification of Species}

All plant species contribute to the structure of a vegetation community so that on an ecological basis all species should be included in an assessment. Even ephemeral species and species that are unresponsive to grazing provide information relevant to the various attributes of condition. Nevertheless the measurement of all species separately may be tedious and unnecessary, and appropriate omission or accumulation of species should be considered. Of primary importance here is to ensure that these adjustments are consistent with the subsequent treatment of the data to form indices of change in the various attributes of condition under question. If the purpose of assessment is to determine change in productivity, the number of species measured can be reduced, both by omitting rare species and by the pooling of others into functional groups, where growth form and reaction to grazing are similar. If, on the other hand, a detailed analysis of vegetation change is required for other purposes, such an accumulation may be inappropriate.

A list of selected species for an $A$. vesicaria low shrubland is shown in Table 2 . This community contains many ephemeral species. Most of these contribute to animal production and a number of them increase in amount as grazing intensity increases. They have been excluded, to avoid the restriction of measurement to short periods of the year and because it is considered that the year-long grazing capacity of this community is related to the presence of the biennial and perennial species. Nevertheless, it must be recognized that the omission of ephemerals may unfairly downgrade some condition classes.

In the assessment of the reaction of species to increased grazing pressure it is customary to classify species in terms of "decreaser" or "increaser" according to the change in their proportion in the community. For most vegetation types this classification is not required for the calculation of indices of vegetation change, except that such classification is useful to identify species that may be used as indicators of various stages of vegetation change. However, for some vegetation types, species classification becomes an integral part of the assessment. In the first instance, decreaser species may be allowed to score above the amount on the refe rence area (reference area value +10 percentage units) without contributing to the index of change (Tainton et al. 1980). More impurtantly, the botanical composition may change several times as the grazing pressure is progressively increased and a simple index of change in botanical composition may award a lower score to intermediate locations than to badly degraded locations. For this reason, increaser species may be classified into type I (increase initially, but later decline as grazing pressure increases) and type II (increase over the whole range) with appropriate correction factors (Poulton 1959). Whilst such systems produce a progressive score of botanical change over the whole range of condition classes, it is not

Table 2. Examples of species present in an Atriplex vesicaria low shrubland (Barrier Range) and their classification for range condition assessment (Wilson and Tupper, unpublished data).

\begin{tabular}{|c|c|c|c|c|}
\hline & $\begin{array}{l}\text { Contribution } \\
\text { to biomass }\end{array}$ & Perenniality & $\begin{array}{l}\text { Response in } \\
\text { grazed community }\end{array}$ & $\begin{array}{l}\text { Classification for } \\
\text { animal production }\end{array}$ \\
\hline Astrebla lappacea & Moderate & Perennial & Increase & Desirable \\
\hline Atriplex conduplicata & ) & Biennial & Increase & JUndesirable \\
\hline A. lindleyi & Moderate & Biennial & Increase & group \\
\hline A. spongiosa & ) & Biennial & Increase & j \\
\hline A. vesicaria & High & Perennial & Decrease & Desirable \\
\hline Arabidella nasturtium & Low & Annual & Increase & Exclude \\
\hline Daucus glochidiatus & Low & Annual & Unresponsive & Exclude \\
\hline Eragrostis setifolia & Low & Perennial & Unresponsive & Desirable \\
\hline Helipterum corymbiflorum & Low & Annual & Increase & Exclude \\
\hline Maireana georgei & Low & Perennial & Decrease & Desirable \\
\hline Sclerolaena brachyptera & Moderate & Biennial & Increase & JDesirable \\
\hline S. diacantha & Moderate & Biennial & Increase & group \\
\hline S. divaricata & Low & Biennial & Increase & Undesirable \\
\hline S. intricata & Low & Biennial & Increase & group \\
\hline Stipa variabilis & Moderate & Biennial & Increase & Intermediate \\
\hline Tetragonia tetragonioides & Moderate & Annual & Unresponsive & Exclude \\
\hline
\end{tabular}


necessarily a linear or useful index of any the attributes of range condition.

The classification of species may be determined from field experience or by graphing the contribution of each species against indices of community change. The technique of reciprocal averaging (Hill 1973) may also be used. This produces an ordination of both species and locations which may be interpretable in terms of a gradient of grazing intensity or vegetation change (Hacker 1979). However, the ordination may overemphasize minor species and be distorted by rare species.

In Natal, South Africa, increaser species are classified into three groups (1-increase when fire or grazing is infrequent; 1 l-increase with overutilization; III - increase with selective grazing) and the total amount of each category is used to indicate the reason for species change (Foran et al. 1978; Tainton et al. 1980). These classifications are a partial move from an index which simply describes botanical change, to one which assesses the value of that change in terms of animal production. It is in part a recognition that not all species change is deleterious and that desirable increaser species are a normal part of many rangeland communities (see Table 2). As a consequence, in assessing condition in terms of change in animal production, it is appropriate to classify species simply in the terms desirable, intermediate and undesirable (as determined by nutritive value, palatability, productivity, etc.), as is done in Western Australia (Payne et al. 1974) and by the U.S. Forest Service (Stoddard et al. 1975).

An example of this type of classification is shown in Table 2. In this case the perennial and biennial species are classified mainly on the basis of palatability. Desirable plants are those that are eaten readily at some period of the year. Undesirable plants are those that are never eaten, or are eaten only sparingly, usually when other forage is scarce. This group may also include plants that are poisonous or have harmful spines or seeds. An intermediate group, comprising plants that are eaten when immature, but are either of low quality or are avoided when mature, may be required in some communities. In the calculation of an index of condition, these species may be counted as half. This separation of change in animal production from change in botanical composition, readily allows for the incorporation of deliberately introduced species, which will be classified as desirable.

\section{Indices of Condition}

The condition of a range unit will be measured initially in terms of the quantity of each plant species present. To be of value to the range manager, this information must be reduced to an index which represents one or more of the attributes of range condition. This is usually accomplished by the calculation of a similarity index (between reference and test areas), of which the Dyksterhuis (1949) Quantitative Climax Index is but one example. A number of others are outlined by Williams (1976) and Orloci (1975). Eight of those with desirable characteristics for measuring vegetation change have been examined by Hacker (1979). His results show the degree of variation in vegetation change that arises simply from the type of index chosen to measure that change. Vegetation change is not an absolute characteristic of a vegetation, and requires some reference to a purpose of measuring that change.

\section{Transformation}

Before proceeding to the calculation of an index, it may be desirable to consider some form of data transformation. Expression of results in terms of percentages (Dyksterhuis 1949) is an example. Other possible transformations include species value/total value ${ }^{0.5}$, (see Smartt et al. 1974) and species value ${ }^{x}$. These may reduce the range of the data or change the relative emphasis given to high or low values; for the practical purpose of making the data less sensitive to recent grazing or to change the relative emphasis given to small or large species or species values. The outcome of some transformations is to reduce the quantitative and increase the qualitative nature of the information (Smartt et al. 1974). Hence percentage transformation eliminates some of the quantitative information in the original data so that it measures only botanical composition and ignores the total quantity of vegetation present. Such a transformation is undesirable for a method that seeks to inform about both of these aspects of vegetation change and hence is inadequate in situations where a decline in condition is expressed in both attributes (e.g. Foran et al. 1978). It may also serve to hide the real nature of change in the community, as an increase in the percentage contribution of a species may represent either a real increase in the quantity of that species, or a decline in the quantity of other species. The deficiencies of percentage transformation may be overcome by adding a second index of species quantity (Foran et al. 1978), but it would be easier to avoid the transformation. An example of quantitative climax scores for two Atriplex vesicaria communities, is given in Table 3 . The relationship between these and scores derived from other indices, will be discussed below.

On the other hand, frequency data may be made more quantitative by the use of power functions (within a species) and correction factors (between species).

\section{Vegetation Change}

When land is to be assessed for its condition in terms of the preservation of natural communities, a measure of vegetation change will be appropriate. Examples of two such indices are shown in Table 3: the Quantitative Climax Index and Percent Similarity (the name is attributed to Hacker 1979). The Percent Similarity is similar to the Quantitative Climax Index in structure, but avoids percentage transformation. It is the sum of the lesser quantity of each species, on the reference and test locations, divided by the sum of all species on the reference location. The index is expressed as a percentage, from 100 (no change) to 0 (complete change). This is a more useful index than the Quantitative Climax Index, because it makes allowance for declines in species quantity, as well as species composition. This procedure is

Table 3. Examples of indices of condition obtained from foliage cover measurements of Atriplex vesicaria communities (Wilson and Tupper, unpublished data).

\begin{tabular}{|c|c|c|c|c|c|c|c|}
\hline \multicolumn{4}{|c|}{ Riverine Plain, N.S.W. } & \multicolumn{4}{|c|}{ Barrier Range, N.S.W. } \\
\hline \multirow[b]{2}{*}{$\begin{array}{c}\text { Location } \\
\text { No. }\end{array}$} & \multicolumn{2}{|c|}{ Indices of vegetation change } & \multirow{2}{*}{$\begin{array}{c}\begin{array}{c}\text { Index of } \\
\text { productivity }\end{array} \\
\text { Relative cover } \\
\text { desirable species }\end{array}$} & \multirow[b]{2}{*}{$\begin{array}{c}\text { Location } \\
\text { No. }\end{array}$} & \multicolumn{2}{|c|}{ Indices of vegetation change } & \multirow{2}{*}{$\begin{array}{c}\begin{array}{c}\text { Index of } \\
\text { productivity }\end{array} \\
\text { Relative cover } \\
\text { desirable species }\end{array}$} \\
\hline & $\begin{array}{l}\text { Percent } \\
\text { similarity }\end{array}$ & $\begin{array}{l}\text { Quantitative } \\
\text { climax }\end{array}$ & & & $\begin{array}{c}\text { Percent } \\
\text { similarity }\end{array}$ & $\begin{array}{l}\text { Quantitative } \\
\text { climax }\end{array}$ & \\
\hline 6 & 100 & 100 & 100 & 8 & 100 & 100 & 100 \\
\hline 4 & 100 & 100 & 100 & 6 & 79 & 87 & 85 \\
\hline 5 & 100 & 95 & 100 & 3 & 78 & 80 & 95 \\
\hline 3 & 49 & 68 & 52 & 1 & 41 & 42 & 73 \\
\hline 8 & 36 & 49 & 43 & 2 & 28 & 26 & 100 \\
\hline 7 & 35 & 56 & 30 & 4 & 24 & 25 & 56 \\
\hline 2 & 22 & 34 & 26 & 5 & 23 & 24 & 30 \\
\hline 1 & 10 & 10 & 16 & 7 & 22 & 25 & 55 \\
\hline
\end{tabular}


outlined in the National Range Handbook (USDA 1976), but the authors understand that it is not often used. Using this method in the Riverine Plain example in Table 3, location numbers 3, 8 and 7 are appropriately penalized for a reduced density of species as well as a change in composition, whereas the first change is not recognized by the Quantitative Climax Index. However, as mentioned earlier, there are many indices of vegetation change (or similarity), and the one chosen will depend on the emphasis to be given to qualitative or quantitative factors, and the particular purpose of the measurement. In retrospect it appears that the Quantitative Climax Index is misnamed.

\section{Productivity}

If change in animal productivity is correlated to change in vegetation attributes in a positive way, then the index of vegetation change may also be used as an index of production. However, in other instances the changes will not be correlated. This will occur in situations where increaser species are valuable and productive for livestock grazing. The example of Sclerolaena spp. is shown in Table 2, and Danthonia caespitosa (Wilson et al. 1969) is another. In these situations, animal production will be related to the total production of useful plants and an index derived from the summation of the biomass or cover of these species will best serve as an index of animal production. An example of this is shown in Table 3. For the Riverine Plain community, the relative cover of desirable species is approximately the same as the Percent Similarity Index, and no benefit arises from the separation of the two. However, for the Barrier Range community, thc contribution of Sclerolaena spp. leads to a substantial difference between the two indices for locations $3,1,2,4$, and 7 . The condition of these locations, in terms of grazing, is not as low as the degree of vegetation change would suggest. In this case it is appropriate to express the results in terms of two indices; the first to be used to characterize condition in terms of vegetation change, and the second in terms of grazing value.

\section{Erosion}

Physical erosion, or more frequently, a decline in the physical characteristics of the soil surface, is the most serious manifestation of a decline in range condition because of its long-lasting and progressive impact on production attributes. As noted by Ellison et al. (1951), condition should be based primarily on soil stability and only secondarily on forage value. He considered that condition is always unsatisfactory unless the soil is stable and that forage value is only considered when the stability is assured. He also suggested that the two factors are not additive. This is consistent with the proposal in this paper, that the various attributes of condition should be measured separately.

Measures of erosion and related soil changes will differ from site to site, according to the type of change experienced. Foran et al. (1978), working in the rangelands of Natal, expressed soil stability in terms of the total basal cover of herbaceous plants. In areas subject to sheet erosion, point sampling can be made of the proportion of soil with a sealed or eroded surface. An example of data from the use of this procedure is shown in Table 4. In this semiarid woodland community, soil erosion is a major manifestation of lowered condition. Indirect measure can also be obtained from changes in the total canopy cover of herbaceous plants. In the example shown in Table 4, total herbage cover reflects the effects of both erosion and shrub encroachment. The Percent Similarity Index or other measures of vegetation change. are of little value in this community as there are no suitable reference areas that are not either shrub invaded or heavily damaged in the past.

Other forms of erosion, such as gullying, are not readily measured and this suggests that the status of the soil will of ten be estimated by subjective ratings, based on indicators such as bare soil surface, erosion pavement, rills and gullies, pedestalling and soil deposition. The ratings developed will be site specific as the importance of each indicator will vary with the site.
Table 4. Indices of condition for a semiarid woodland in New South Wales, in which declining condition is characterized by both erosion and increasing density of inedible shrub (Wilson, et al., unpublished data).

\begin{tabular}{ccccc}
\hline \hline Location & $\begin{array}{c}\text { Relative }^{1} \\
\text { herbage } \\
\text { Nover }\end{array}$ & $\begin{array}{c}\text { Inedible } \\
\text { shrub } \\
\text { cover } \\
(\%)\end{array}$ & $\begin{array}{c}\text { Soil2 } \\
\text { erosion } \\
\text { index }\end{array}$ & $\begin{array}{c}\text { Percent }^{3} \\
\text { similarity }\end{array}$ \\
\hline 4 & 100 & 11 & 34 & 100 \\
9 & 79 & 10 & 54 & 38 \\
5 & 74 & 30 & 12 & 51 \\
1 & 72 & 15 & 58 & 35 \\
8 & 72 & 12 & 88 & 29 \\
3 & 65 & 7 & 87 & 25 \\
10 & 56 & 30 & 61 & 36 \\
11 & 36 & 33 & 36 & 32 \\
2 & 25 & 32 & 95 & 17 \\
7 & 24 & 25 & 91 & 21 \\
6 & 7 & 34 & 87 & 12 \\
\hline
\end{tabular}

'Cover of desirable perennial species, relative to location 4 .

2Percentage of eroded soil surface.

${ }^{3}$ Relative to location 4 , includes shrub and herbage species. (Not different to quantitative climax indices in this instance).

\section{Shrub Encroachment}

The encroachment of inedible shrubs and trees into semiarid rangelands represents a community change that may be viewed either as a change in botanical composition or as a separate vegetation attribute: the herbaceous-woody species balance. In terms of a change of botanical composition there is some difficulty in measuring shrub weight or cover in equivalent terms to herbaceous plants, but appropriate indices of condition could be constructed in this way. Alternatively, the measurements may be confined to the herbage layer. The total herbage cover (see Table 4) is in itself a direct measure of the effects of shrub encroachment and may be used as an integrated index of condition in terms of productivity. In terms of separate attribute of condition, a simple index of shrub encroachment can be constructed. The nature of the effect of shrub biomass on herbage biomass is shown in Figure 1. This type of relationship, for either biomass or cover, could be determined for each community type and used to develop a scale for assessing the condition of shrub cover. Such an index of shrub encroachment will be directly related to potential animal production.

Such indices of shrub encroachment may be an incomplete measure of the situation, particularly when the shrubs are not fully

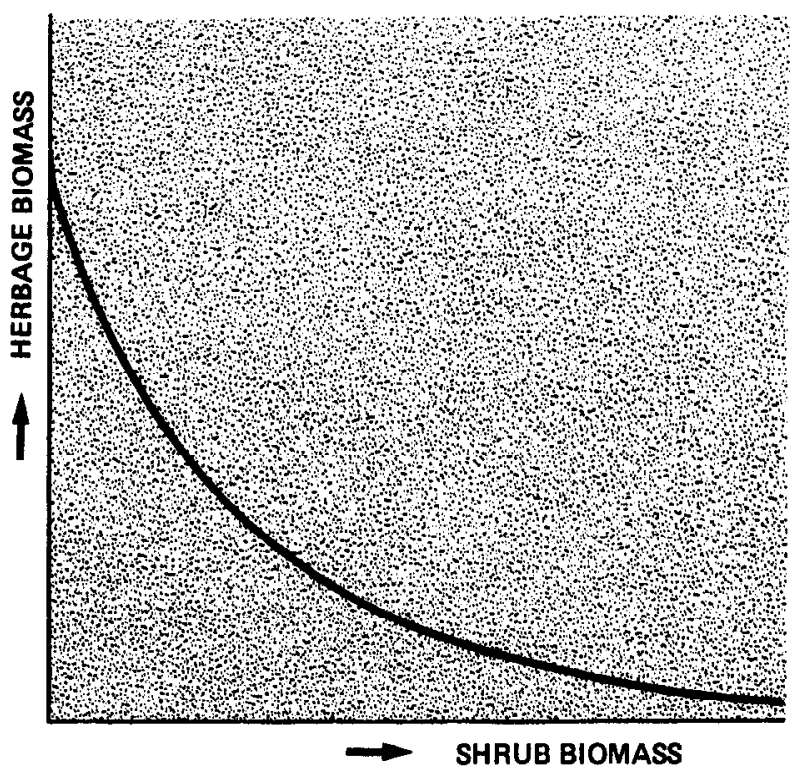

Fig. 1. Relation between herbage yield and shrub biomass (adapted from Beale 1973). 
established and represent an incipient rather than a current problem. Separate measure of shrub seedling density may be required and these would be considered as an assessment of the trend in condition, rather than condition itself.

\section{Discussion}

There are a number of steps involved in the development of any method of range condition; the choice of vegetation measure, the species to be included and their classification, and the type of index to be constructed. At each step, the choice made from the available methods and systems is dependent on the current land use and the attribute of condition to be assessed. The appropriatc concepts and methods of ecology may be incorporated into an assessment system, but this does not lead to a single ecological method or scale that may be regarded as a universal standard of condition. Range condition is a concept, like succession, which manifests itself in different forms according to the community type and to the disturbance applied. In particular, the community changes may be either quantitative or qualitative, or both, and the consequences of each change for soil stability or secondary production will differ according to the type of species involved and the erodibility of the soil. The idea of an "ecological method" based on some absolute change in botanical composition has been appealing. It has been supported by general statements that it is an "objective ecological approach" (USDA 1976) without acknowledging that there are other attributes of change in condition or even that there are a number of ways of measuring change in botanical composition. It has gained credence because of an assumed general relationship between animal productivity and change in botanical composition (Dyksterhuis 1949). In other situations this method has required extensive modification to make it functional (Foran et al. 1978, Smith 1979). It is now apparent that it is only one of a number of possible methods and that it provides only a part of the framework of range condition.

There has been a long standing difference of opinion between authors on whether range condition methods should be based on productivity or ecology (Humphrey 1949; Dyksterhuis 1949). It may now be concluded that ecological and productivity-based methods are not mutually exclusive. Changes in botanical attributes and change in production attributes are scparate, but related aspects of range condition. Neither can be said to be more important than the other without reference to the purpose of assessment. In general, ecological methods require the consideration of production attributes for interpretation, while productivity is a state of the vegetation that is dependent on species composition and density and requires ecological techniques for its measurement. Range condition is not wholly defincd by, or equivalent to, botanical composition as previously claimed by Dyksterhuis (1958).

In practice, composite indices of va rious attributes of condition may be constructed (e.g. Foran et al. 1978), but these then refer indirectly to a production attribute of condition. Perhaps it is inevitable that all indices of condition on grazed rangeland will refer either to soil stability or to production change (animals and other products), as in such agricultural situations vegetation change in itself does not have a value. It is the importance of that change in terms of production characteristics that is of concern. Agriculture in general is based on the modification or replacement of natural vegetation, and rangeland, although only partially modified, must be assessed on the same basis. Also, in most parts of the world, the concept of vegetation change from original has no basis as no original vegetation remains. In such cases the benchmark or reference vegetation will be constructed in terms of a production attribute. It is therefore concluded that range condition should be expressed as separate indices of soil stability and of important production attributes, despite the use of ecological techniques to measure the vegetation. Associated scales of vegetation change may also be derived in appropriate situations, but these will be used for the separate purpose of assessing land for the conservation of plant communities.

A common subjective classification of condition assessments across all rangeland types could be developed from within the framework presented by Ellison et al. (1951). A re-interpretation of this is as follows:

Excellent condition: soil stable, productivity good

Good condition: soil stable, productivity diminished

Fair condition: soil unstable, productivity good

Poor condition: soil unstable, productivity diminished.

This would avoid differences in interpretation that currently occur between range types and between countries.

One consequence of this interpretation of range condition, is that each range type may have a different system of assessment. Each system will be based on the type of degradation found under current land use and on the structure of the vegetation community. The detail of methods may also change as new insights are gained into the function of those communities and the value of their component species. Nevertheless, the one set of data may be applied to assessments for many land uses, as the major differences between systems will be in the construction of condition indices, rather than in the technique of ficld measurement.

\section{Literature Cited}

Beale, I.F. 1973. Tree density effects on yields of herbage and tree components in south west Queensland Mulga (Acacia aneura F. Muell.) scrub. Trop. Grassl. 7:135-42.

Christie, E.K. 1978. Herbage condition assessment of an infertile range grassland based on site production potential. Aust. Range. J. 1:87-94.

Dyksterhuis, E.J. 1949. Condition and management of rangeland based on quantitative ecology. J. Range Manage. 2:104-15.

Dyksterhuis, E.J. 1958. Range conservation as based on sites and condition classes. J. Soil Water Conserv. 13:151-55.

Eltison, L., A.R. Croft, and R.W. Bailey. 1951. Indicators of condition and trend on hig range-watersheds of the Intermountain range. USDA Agriculture handbook No. $19.66 \mathrm{p}$.

Foran, B.D., N.M. Tainton, and P.deV. Booysen. 1978. The development of method for assessing veld condition in three grassveld types in Natal. Proc. Grassld. Soc. South Afr. 13:27-33.

Gates, D.H. 1979. The use of range condition in rangeland ecosystem evaluation and management planning. In: K.M.W. Howes (ed.). Rangeland Ecosystem Evaluation and Management. Aust. Range. Soc. Perth.

Greig-Smith, P. 1964. Quantitative Plant Ecology. Butterworths, London. $256 \mathrm{p}$.

Hacker, R.B. 1979. Studies of the ecology and range condition of two arid ecosystems. PhD Thesis, Univ. New South Wales. 505 p.

Hill, M.0. 1973. Reciprocal averaging: an eigen-vector method of ordination. J. Ecol. 61:237-49.

Humphrey, R.R. 1949. Field comments on the range condition method of forage survey. J. Range Manage. 2:1-10.

Naveh, Z. 1975. Range condition and trend. In: D.J. Pratt and M.D. Gwynne (eds). Rangeland Management and Ecology in East Africa. Hodder and Stoughton, London, p. 94-99.

Orloci, L. 1975. Multivariate Analysis in Vegetation Research. Junk, The Hague. 276 p.

Payne, A.L., A. Kubicki, and D.G. Wilcox. 1974. Range condition guides for the West Kimberley area W.A. Western Australian Department of Agriculture. $141 \mathrm{p}$.

Poulton, C.E. 1959. Ecology for the land manager. A clarification of ecological principles, concepts and philosophies. Corvallis, Oregon State Univ., Range Science. Mimeo 16 p. As cited by Tueller, P.T. 1973. In: D.N. Hyder (ed.). Arid Shrublands. Proc. 3rd Workshop US/Aust. Rangelands Panel, Tucson p. 57-65.

Smartt, P.F.M., S.E. Meacock, and J.M. Lambert. 1974. Investigations into the properties of quantitative vegetational data. I. Pilot study. J. Ecol. 62:735-59.

Smith, E. Lamar. 1979. A critical evaluation of the range condition concept. Proc. Ist Internat. Range. Congr., Denver, p. 266-7.

Stoddart, L.A., A.D. Smith, and T.W. Bux. 1975. Range Management. McGraw-Hill, New York. 532 p.

Tainton, N.M., P.J. Edwards, and M.T. Mentis. 1980. A revised method for assessing veld condition. Proc. Grass. Soc. South. Afr. 15:37-42.

United States Department of Agriculture. 1976. National Range Handbook. Soil Conserv. Serv.

Williams, W.T. 1976. Pattern Analysis in Agricultural Science. CSIRO, Melbourne. 331 p.

Wilson, A.D., J.H. Leigh, and W.E. Mulham. 1969. A study of Meroin sheep grazing a bladder saltbush (Atriplex vesicaria) - a cotton bush (Kochia aphylla) community on the Riverine Plain. Aust. I. Agr. Res. 20:1123-36. 